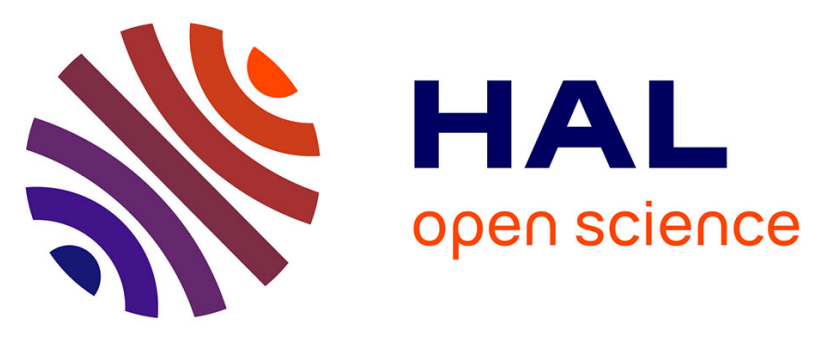

\title{
Impact of take-home messages written into slide presentations delivered during lectures on the retention of messages and the residents' knowledge: a randomized controlled study
}

Alexandre Lautrette, Alexandre Boyer, Didier Gruson, Laurent Argaud, Carole Schwebel, Bernard Tardy, Philippe Vignon, Bruno Mégarbane, Pierre Schoeffler, Pascal Chabrot, et al.

\section{- To cite this version:}

Alexandre Lautrette, Alexandre Boyer, Didier Gruson, Laurent Argaud, Carole Schwebel, et al.. Impact of take-home messages written into slide presentations delivered during lectures on the retention of messages and the residents' knowledge: a randomized controlled study. BMC Medical Education, 2020, 20 (1), pp.180. 10.1186/s12909-020-02092-7 . hal-02778928

\author{
HAL Id: hal-02778928 \\ https://hal.science/hal-02778928
}

Submitted on 24 Sep 2020

HAL is a multi-disciplinary open access archive for the deposit and dissemination of scientific research documents, whether they are published or not. The documents may come from teaching and research institutions in France or abroad, or from public or private research centers.
L'archive ouverte pluridisciplinaire HAL, est destinée au dépôt et à la diffusion de documents scientifiques de niveau recherche, publiés ou non, émanant des établissements d'enseignement et de recherche français ou étrangers, des laboratoires publics ou privés. 


\title{
Impact of take-home messages written into slide presentations delivered during lectures on the retention of messages and the residents' knowledge: a randomized controlled study
}

\author{
Alexandre Lautrette ${ }^{1,2,3^{*}}$, Alexandre Boyer ${ }^{4}$, Didier Gruson ${ }^{4}$, Laurent Argaud ${ }^{5}$, Carole Schwebel $^{6}$, Bernard Tardy ${ }^{7}$, \\ Philippe Vignon ${ }^{8}$, Bruno Megarbane ${ }^{9}$, Pierre Schoeffler ${ }^{10}$, Pascal Chabrot $^{11}$, Jeannot Schmidt ${ }^{12}$, Yves Boirie $^{13}$, \\ Claude Guerin ${ }^{14}$, Michaël Darmon ${ }^{15}$, Kada Klouche ${ }^{16}$, Bertrand Souweine ${ }^{3,17}$, Jean Dellamonica ${ }^{18}$, \\ Bruno Pereira ${ }^{19}$ and for the TREX group
}

\begin{abstract}
Background: Lectures with slide presentations are widely used to teach evidence-based medicine to large groups. Take-home messages (THMs) are poorly identified and recollected by students. We investigated whether an instruction to list THMs in written form on slides would improve the retention thereof by residents, and the residents' level of knowledge, 1 month after lectures.

Methods: Prospective blinded randomized controlled study was conducted. Twelve lectures ( 6 control and 6 intervention lectures) were delivered to 73 residents. For the intervention lectures, the lecturers were instructed to incorporate clear written THMs into their slide presentations. The outcomes were ability of resident to recollect THMs delivered during a lecture (as assessed by accordance rate between the lecturers' and residents' THMs) and knowledge (as assessed by multiple choice questions (MCQs)).

Results: Data for 3738 residents' THMs and 3410 MCQs were analyzed. The intervention did not significantly increase the number of THMs written on slides (77\% $(n=20 / 26), 95 \% \mathrm{Cl} 56-91$ vs $64 \%(n=18 / 28), 95 \% \mathrm{Cl} 44-81$, $p=0.31)$ nor THMs retention $(13 \%(n=238 / 1791), 95 \% \mathrm{Cl} 12-15$ vs $17 \%(n=326 / 1947), 95 \% 15-18, p=0.40)$ nor knowledge (63.8 \pm 26.2 vs $61.1 \pm 31.4 / 100$ points, $p=0.75)$. In multivariable analyses performed with all THMs written on slides from the two groups, a superior knowledge was associated with notetaking during lectures (OR 1.88, 95\% Cl 1.41-2.51) and THMs retention (OR 2.17, 95\% Cl 1.54-3.04); and THMs retention was associated with written THMs (OR 2.94, 95\% Cl 2.20-3.93).
\end{abstract}

(Continued on next page)

\footnotetext{
* Correspondence: alautrette@chu-clermontferrand.fr

'Intensive Care Medicine, Gabriel Montpied Hospital, University Hospital of Clermont-Ferrand, Clermont-Ferrand, France

${ }^{2}$ Intensive Care Unit, Centre Jean Perrin, Clermont-Ferrand, France

Full list of author information is available at the end of the article
}

C C The Author(s). 2020 Open Access This article is licensed under a Creative Commons Attribution 4.0 International License, which permits use, sharing, adaptation, distribution and reproduction in any medium or format, as long as you give appropriate credit to the original author(s) and the source, provide a link to the Creative Commons licence, and indicate if changes were made. The images or other third party material in this article are included in the article's Creative Commons licence, unless indicated otherwise in a credit line to the material. If material is not included in the article's Creative Commons licence and your intended use is not permitted by statutory regulation or exceeds the permitted use, you will need to obtain permission directly from the copyright holder. To view a copy of this licence, visit http://creativecommons.org/licenses/by/4.0/ The Creative Commons Public Domain Dedication waiver (http://creativecommons.org/publicdomain/zero/1.0/) applies to the data made available in this article, unless otherwise stated in a credit line to the data. 


\begin{abstract}
(Continued from previous page)
Conclusions: In lectures delivered to residents, a third of the THMs were not in written form. An intervention based on an explicit instruction to lecturers to provide THMs in written form in their slide presentations did not result in increased use of written THMs into the slide presentation or improvement of the THMs retention or level of knowledge. However, we showed that there was a strong positive association between writing THMs on a slide, retention of THMs and residents' knowledge. Further researches are needed to assess interventions to increase written THMs in lectures by faculty.
\end{abstract}

Trial registration: ClinicalTrials.gov NCT01795651 (Fev 21, 2013).

Keywords: Medical education, Resident, Lecture, Knowledge, Take-home message

\section{Background}

Medical education is fundamental to improve the quality of health care but also poses great challenges [1]. Several approaches, such as the diversification of learning methods, have been explored to improve the quality of medical education. The emergence of simulation or problem-based learning has improved skill and competency training and had a positive impact on clinical practice [2]. These educational techniques are applied in small-groups settings to obtain immediate and personalized feedback $[3,4]$. Another way to improve medical education is to enhance the effectiveness of teaching strategies [5]. Conventional methods, which are widely used to teach evidence-based medicine (EBM), are being revolutionized by the incorporation of modern communication modalities into textbooks, such as videos (Quick Response (QR) code) and audio files, and by videoclips inserted into slides for lecture presentations, and videorecorded e-learning lectures [6,7]. Although students appreciate the wide availability of video-based learning, face-to-face education continues to be relevant and offers a contextualized educational approach [8]. In this approach, illustrative examples are provided, tailored to the audience; this promotes involvement of students and is relevant to EBM $[8,9]$. Several studies have reported that face-to-face lectures are as effective as e-learning using video-recorded lectures for teaching EBM $[10,11]$. However, as with all educational approaches, the efficacy of these methods is poor [10]. Currently, almost all faceto-face lectures and a large proportion of e-learning approaches, rely on slide presentations $[12,13]$ to highlight take-home messages (THMs). We previously reported a major failure to identify THMs by Intensive Care Unit (ICU) residents during face-to-face lectures based on slide presentations [14]. Two-thirds of ICU residents identified, at best, only one of the three main THMs at the end of lecture. We postulated that THMs in written form on slides could improve this retention because the identification of THM would be easier and the lecturer would take time to stress the mind on the message to remember. In this study, we investigated whether instructing teachers clearly to write THMs on their slide presentations would improve the rate of retention thereof by residents, and residents' knowledge assessed 1 month after a critical care lecture.

\section{Methods}

\section{Study setting and participants}

We conducted a prospective randomized controlled blinded study at the University of Clermont-Ferrand, France, in February 2013 during the delivery of an ICU educational module (part of a postgraduate Intensive Care Unit (ICU) diploma program) attended by $25 \%$ of the national residents enrolled on the ICU training course. We enrolled all residents and lecturers who took part in the module into this study, except those who refused to participate. Written informed consent was obtained retrospectively from lecturers and prospectively from residents. The study protocol was approved by the Ethics Committee of the French Intensive Care Society (CE SRLF, No.12-394) and the local Institutional Review Board (IRB00008526, No.201837) in accordance with French law. The study was registered on the Clinical Trials Registry (clinicaltrials.gov) NCT01795651.

\section{Study design and intervention}

The educational module was delivered over 5 consecutive days during which 12 expert lecturers each gave a single lecture pertaining to EBM for critical illness (Additional file 1). The residents were instructed to attend all lectures and they were blinded to the intervention. They were sent the lecture topics 1 month before the module and therefore had the opportunity to prepare questions in advance. Interaction between the audience and lecturers was actively encouraged. All lecturers were experienced teachers who attended faculty workshops on effective lecture presentations, including how to devise an educational slide presentation and communicate THMs.

Two months before the educational module, the lecturers were randomly assigned in a 1:1 ratio to the intervention or control lectures group, by permuted-block randomization (i.e. random block sizes) using a computer-generated random allocation (Stata software). They were blinded to the study and their group 
assignment during the preparation and delivery of their lecture. The title and educational objectives of the lecture were chosen by the lecturer. The invitation e-mail provided information on the lecture conditions (face-toface lecture with a slide presentation), the duration (30 min followed by $15 \mathrm{~min}$ for questions) and the learners' characteristics (postgraduate resident doctors enrolled on an ICU training programme). At 1 month and at 1 week before the beginning of the module, a reminder email was sent to each lecturer. The intervention element of the study was an explicit instruction to lecturers to include at least one slide entitled "Message" or "Takehome Message" into their slide presentations containing the written THM, for each THM delivered. A THM was defined as a short message of key relevant to medical practice. The number of THMs was limited to five per lecture. The choice and the wording of the THMs were decided on the lecturer. Each written THM was limited to 15 words. The instruction to the lecturers was clearly stated in a separate paragraph within the e-mail, which also included an article reporting the failure of residents to identify THMs in ICU postgraduate lectures [14]. The email did not mention that the lecture to be delivered was part of an experimental study. In the final part of the e-mails, the lecturers were encouraged to contact us for further details in the event of any problems or misunderstanding. The lecturers in the control group received only the three invitation e-mails, while those in the intervention group received the three e-mails including the instructional paragraph.

The lecturers were later informed about the study at the end of their lecture. All accepted to take part in the study. After the lecture, the lecturers provided the investigators with up to five THMs ( $\leq 15$ words per THM) that they had included in their lecture, and a maximum of five multiple choice questions (MCQs) with answers related to their THMs. The lecturers in the two groups indicated if their THMs had been explicitly written or not in the slide presentation. For all 12 lectures, two blinded teacher-reviewers compared the THMs written on slides in the slide presentation of the lecturer with the report of THMs written or not on slides given by lecturer after the lecture. There was no disagreement between lecturers and reviewers. This assessment validated the THMs written or not on slides in all lectures.

The residents were informed about the study and gave consent to participate on the first day of the module, before the first lecture. However, they were blinded to the precise nature of the intervention, and to the outcomes, although they knew that they would be contacted 1 month after the final lecture to assess their knowledge of the module's content. This assessment was not associated with other stake for the residents. One month after the last lecture, the residents completed an assessment form sent by e-mail. For each lecture, they were asked if they had attended the lecture, the THMs that they recollect ( $\leq 15$ words per THM) and whether they had taken notes (defined as writing down the key points of the lecture). The definition of a THM was provided in the email. The number of THMs delivered by the lecturer during each lecture was specified in assessment form. The residents did not have access to slide presentations but could consult their notes or learning materials when answering the assessment. They were allowed to give one additional THM to the number of THMs delivered during the lecture to increase the opportunity to recollect the THMs delivered by lecturer. Finally, they answered MCQs related to the different THMs. For each $M C Q$, the residents were given the number of correct answers (Additional file 2). Two reminder e-mails were sent to residents who did not reply; if there was still no reply, they were secondarily excluded (Additional file 3).

\section{Outcomes}

The primary outcome was the difference in THMs retention as assessed by the rate of accordance between the THMs delivered by lecturers and given by residents, between the intervention and control lectures. The accordance was independently determined by two reviewers who were intensivist teachers but not lecturers on the educational module. They were also blinded to two group assignments. A binary scoring system was used: "Yes" when there was clearly a match between the resident and lecturer messages, and "No" to all other cases. If there was disagreement between the reviewers after a second analysis of THM accordance, a third reviewer analysed the data (disagreement arose in $4.6 \%$, of the evaluation, $n=174 / 3738$ ). The order in which the THMs were listed on the responses forms was not taken into account in the analysis.

The second outcomes were 1) the difference in residents' level of knowledge, as assessed by the MCQ, between the intervention and control lectures, 2) the identification of factors associated with better THMs retention or knowledge.

Each MCQ was rated 0 if there was at least one error among resident answers or 1 if there was no error. The knowledge of a resident was assessed for each lecture with a score based on the MCQs related to the lecture (total possible score, 100 points). Three groups of residents' level of knowledge were established according to relevance and statistical distribution (interquartile range): low performance ( $<50$ points), medium performance ( $50-80$ points) and high performance ( $>80$ points). If a resident failed to attend a lecture, no score was recorded.

\section{Statistical analysis}

At least 70 residents would participate in the educational module. Assuming that they would all attend all 12 
lectures, 420 assessment forms were expected per lecture groups. In our previous observational study, the THM accordance rate observed was 39\% at the end of lecture [14]. In the present study, the primary endpoint was assessed 1 month after the last lecture. Therefore, we assumed a $50 \%$ relative decrease in accordance, such that the expected THM accordance rate was $20 \%$. For a twosided type I error at 5\%, 3500 residents' THMs (i.e. 1750 THMs per lecture group) would have a power of $80 \%$ to show an absolute difference of $5 \%$ (20\% vs. $25 \%)$, taking into account between- and within- resident's variability measured using intra-cluster correlation coefficient.

All statistical analyses were performed with Stata statistical software (version 13, StataCorp, College Station, US). Categorical data are expressed as numbers and percentages, and quantitative parameters as mean \pm standard-deviation (SD) or median [interquartile range], according to statistical distribution. The normality of the data was assessed using the Shapiro-Wilk's test. To take into account variability between and within lecturers and residents, random-effect models were generated (lecturers and residents as crossed random effects). These models (generalized linear mixed model with logit link function) were used to determine factors associated with THMs retention and residents' knowledge. Multivariable analyses were then performed, with covariates (fixed effects) determined according to their significance in univariate analysis $(P<0.10)$ and clinical relevance, for THMs retention: gender, slides per lecture, notetaking and THMs written on slides; for residents' knowledge: gender, notetaking and THMs retention. Particular attention was paid to multicollinearity and the interactions between covariates, and the impact of adding variables to, or omitting them from, the multivariable model. Results were expressed as odds-ratios (OR) or adjusted odds-ratios (aOR) for multivariable analyses and $95 \%$ confidence intervals $(95 \% \mathrm{CI})$. Sensitivity analysis was conducted with THMs retention rate treated as a continuous variable (using negative binomial generalized linear mixed model) and categorized according to various cut-offs, such as a cut-off of $25 \%$ determined according to the expected assumption used for sample size estimation.

\section{Results}

Of the 79 eligible residents who attended the educational module, 4 declined to participate and 2 did not return the questionnaire and were then secondarily excluded (Fig. 1). The data from 73 residents were finally analyzed. The residents population was predominantly male $(n=50,68 \%)$ with an age of $31 \pm 3$ years and $2 \pm 1$ years of ICU experience. The two lecturer groups were similar at baseline in terms of general characteristics and lecture characteristics (Table 1). Each of the 12 lectures was attended by a mean of 71 residents, achieving the analysis of 853 scores, 3738 residents' THMs and 3410 MCQs.

\section{Assessment of THMs retention}

The number of written THMs incorporated into the slide presentations did not differ between the intervention and control groups $(77 \%(n=20 / 26), 95 \%$ CI $56-91$ vs $64 \%(n=18 / 28), 95 \%$ CI $44-81, P=0.31)$. The rate of THMs retention was not different between the intervention and control groups $(13 \% \quad(n=238 / 1791), 95 \%$ CI $12-15$ vs $17 \%(n=326 / 1947), 95 \%$ CI $15-18, P=0.40)$ (Fig. 2).

\section{Assessment of residents' knowledge}

Residents' knowledge was assessed by $22 \mathrm{MCQs}$ related to the THMs in the intervention lectures, and by 26 MCQs in the control lectures. The level of knowledge in the intervention lectures did not have higher than that in the control lecture $(63.8 \pm 26.2$ vs $61.1 \pm 31.4$ points, $P=0.75)$.

\section{Impact of written THMs on a slide on THMs retention}

Of the 54 THMs delivered during the 12 lectures, 38 (70\%) appeared in written form on a slide. The THMs retention was higher for written THMs compared to THMs delivered only orally $(18 \%(n=473 / 2630), 95 \%$ CI $17-20$ vs $8 \%(n=91 / 1108), 95 \%$ CI $7-10, P<0.001)$ (Fig. 2$)$. In univariate (Table 2) and multivariable analysis adjusted for randomization lectures group and the number of slides, the factors associated with THMs retention were the writing of THMs on slides $(\mathrm{aOR}=2.94,95 \%$ CI 2.20-3.93; $P<$ 0.001 ) and notetaking by resident during the lecture $(\mathrm{aOR}=2.05,95 \% \mathrm{CI} 1.70-2.48 ; P<0.001)$.

\section{Impact of THMs retention on residents' knowledge}

The relationship between THMs retention and residents' knowledge was significant $(P<0.001)$ : the THMs retention was $10.9 \pm 16.1 \%, 13.0 \pm 18.5 \%$ and $22.3 \pm 25.2 \%$ in the low-, medium-, and high-performance groups, respectively. Univariate analyses comparing knowledge, gender, notetaking (yes/no) and THMs retention ( $\leq$ or $>$ $25 \%)$ between the control and intervention lectures groups are shown in Table 3. In the multivariable analysis adjusted for randomization group and gender, better knowledge was associated with notetaking $(\mathrm{aOR}=$ $1.88,95 \%$ CI $1.41-2.51 ; p<0.001)$ and a higher rate of THMs retention $(\mathrm{aOR}=2.17,95 \%$ CI $1.54-3.04 ; p<$ $0.001)$. Sensitivity analysis with THMs retention as continuous variable $(\mathrm{aOR}=1.02,95 \%$ CI 1.01-1.03, $p<$ 0.001 ), and then with THMs retention thresholds of $20 \%$ $(\mathrm{aOR}=1.69,95 \% \mathrm{CI} 1.26-2.26, p<0.001)$ and $30 \%$ $(\mathrm{aOR}=2.24,95 \%$ CI $1.56-3.22, p<0.001)$, was conducted to verify that this choice of THMs retention threshold did not affect the relationship between THMs retention and knowledge. 


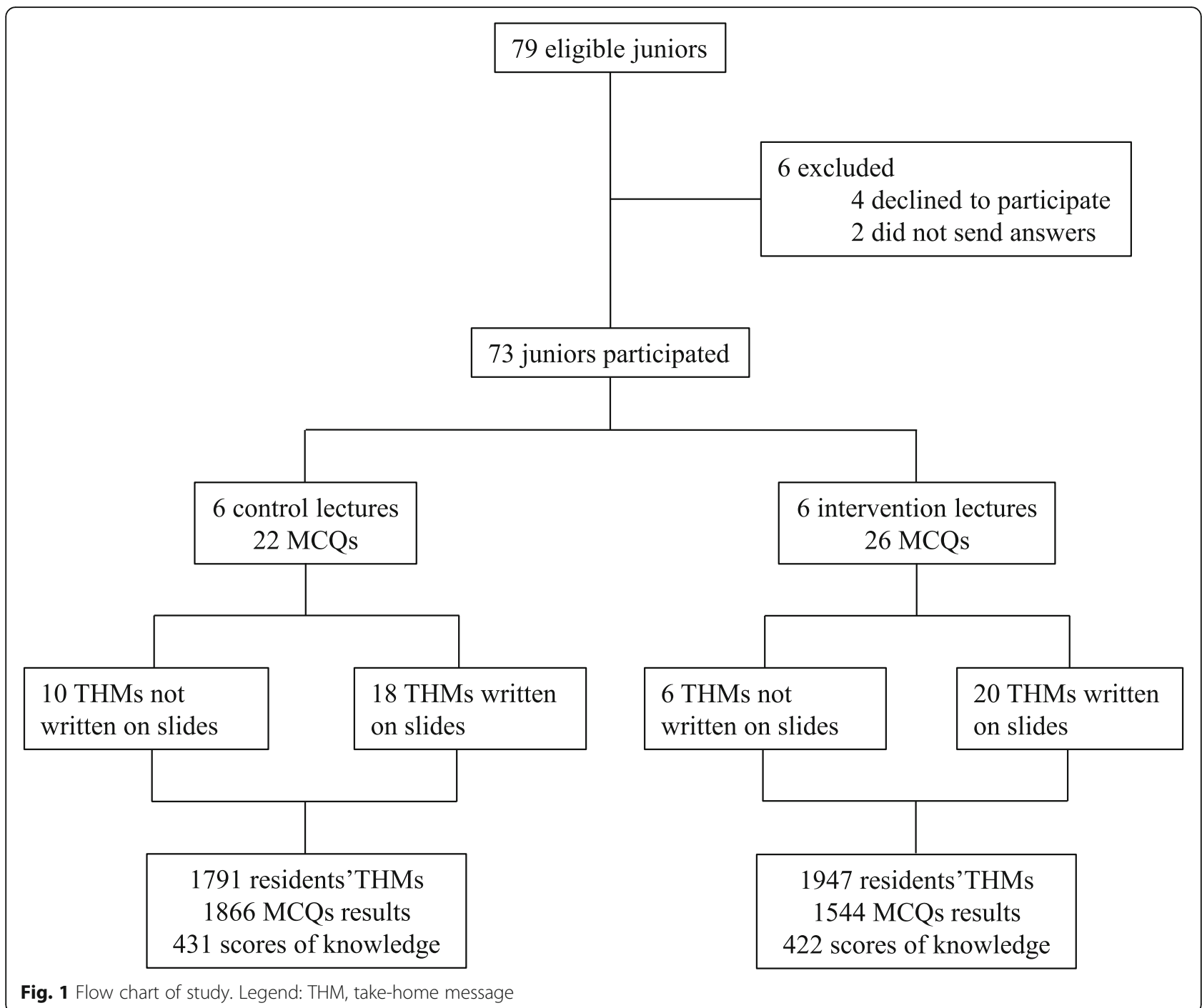

\section{Discussion}

In this study, an intervention based on explicit instructions to lecturers to provide THMs in written form in their slide presentations did not result in increased use of written THMs into the slide presentation or improvement of the THMs retention or level of knowledge, 1 month after a lecture. However, the multivariable analyses performed with all THMs written on slides, whatever the group, showed that the writing of THMs on slides increased THMs

Table 1 Characteristics of lectures and lecturers

\begin{tabular}{|c|c|c|c|}
\hline Variable & $\begin{array}{l}\text { Lecturers } \\
n=12\end{array}$ & $\begin{array}{l}\text { Control group } \\
n=6\end{array}$ & $\begin{array}{l}\text { Intervention group } \\
n=6\end{array}$ \\
\hline Male, n (\%) & $11(92)$ & $6(100)$ & $5(83)$ \\
\hline Teaching experience (years), mean $\pm \mathrm{SD}$ & $22 \pm 10$ & $23 \pm 10$ & $21 \pm 11$ \\
\hline Professor of medicine, $\mathrm{n}(\%)$ & $11(92)$ & $5(83)$ & $6(100)$ \\
\hline Lecture delivered in the afternoon, $\mathrm{n}(\%)$ & $6(50)$ & $2(33)$ & $4(67)$ \\
\hline Slides per lecture (number), mean \pm SD & $53 \pm 12$ & $50 \pm 9$ & $56 \pm 15$ \\
\hline THMs per lecture (number), mean \pm SD & $4.5 \pm 0.8$ & $4.7 \pm 0.5$ & $4.3 \pm 1.0$ \\
\hline Written THMs per lecture (number), mean \pm SD & $3.2 \pm 1.4$ & $3.0 \pm 1.4$ & $3.3 \pm 1.5$ \\
\hline MCQs per lecture (number), mean $\pm S D$ & $4.0 \pm 0.9$ & $4.3 \pm 0.8$ & $3.7 \pm 0.8$ \\
\hline
\end{tabular}

THM take-home message, MCQ multiple choice question 


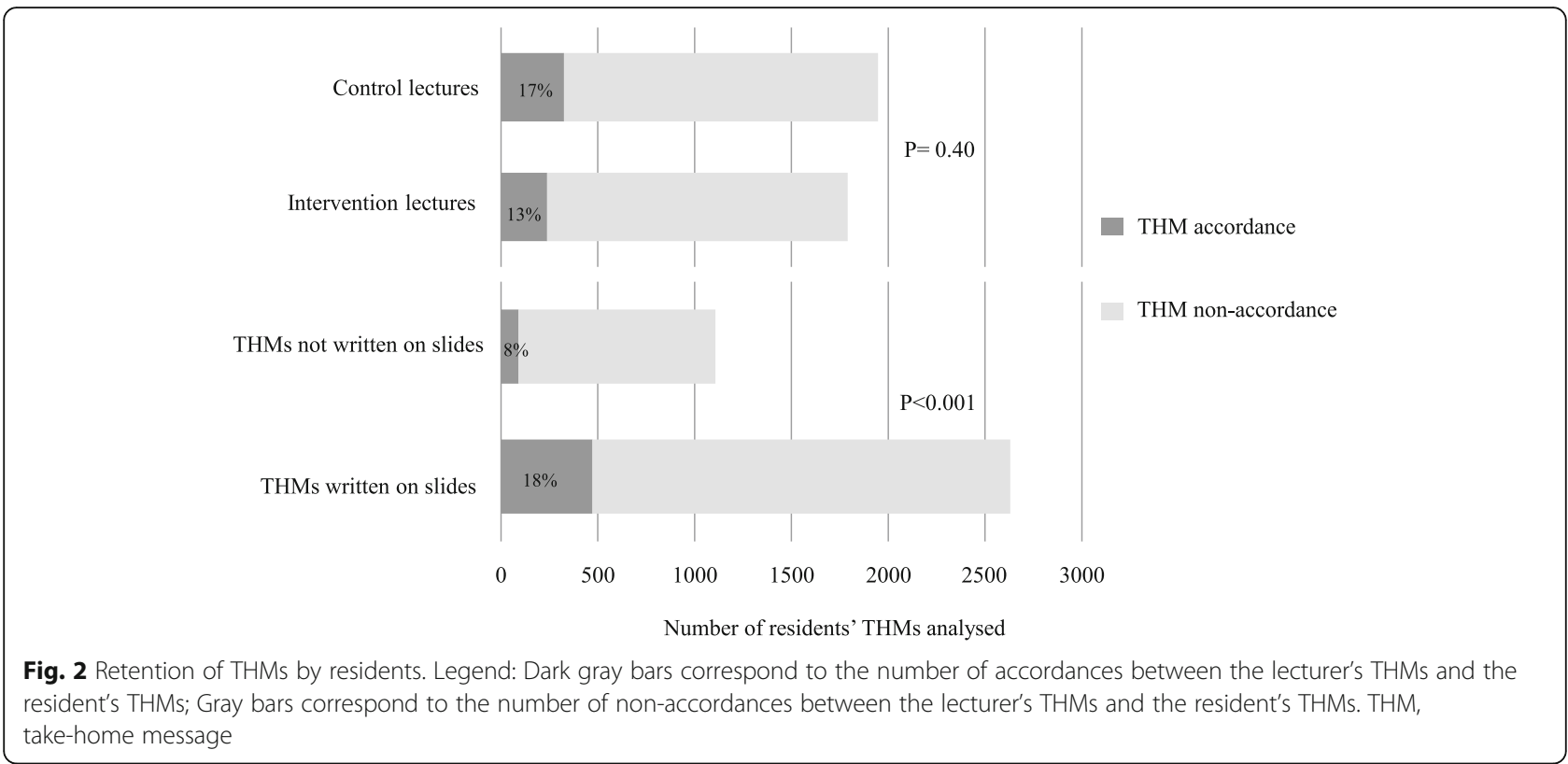

retention that was strongly associated with better residents' knowledge.

The intervention assessed in our study aimed to increase the number of THMs written on slides. But the lecturers in the intervention group who were instructed to provide written THMs did not significantly change their educational practice during the study, such that there was no difference between the two lectures groups in rate of THMs retention or level of knowledge. There are several possible explanations. Firstly, the instructions provided to the intervention group may have been insufficiently clear, although the request was easy to implement for teachers with experience in giving slide presentations. We encouraged the lecturers to contact us if they encountered any problems or required further information. None did so. Secondly, we cannot rule out the possibility that the lecturers in the intervention group were unwilling to modify the format of their presentation. They may have thought that the THMs delivered during their lecture were already effectively communicated during their slide presentation. However, our results point to the opposite conclusion. Although the intervention was ineffective, the data from multivariate analyses performed with all written THMs from both groups, support the original hypothesis that written THMs are valuable. Findings from learning studies suggest that messages are more easily identified when written as a short passage of text that can be readily assimilated by the learner $[15,16]$. The writing of short THMs on a slide makes notetaking easier for trainees [17]. The notetaking from written THMs contain key terminology related to the topic, which is of great help for understanding and recollecting the lecture content. The transfer of THMs is achieved orally by listening to the lecture and visually by looking at the slide presentation [17]. We instructed the lecturers to use a specific THM format but did not make it mandatory, which could have led to a significant, but artificial, difference. Changing methods or practices is highly challenging, despite convincing data published in major journals

Table 2 Univariate analysis of THMs retention

\begin{tabular}{llll}
\hline Variable & $\begin{array}{l}\text { THM non-accordance } \\
n=3174\end{array}$ & $\begin{array}{l}\text { THM accordance } \\
n=564\end{array}$ & OR [95\% Cl], $P$ value \\
\hline Intervention lectures, $\mathrm{n}(\%)$ & $1553(48.9)$ & $238(42.2)$ & $0.79[0.45-1.38], p=0.40$ \\
Male, $\mathrm{n}(\%)$ & $2202(69.4)$ & $381(67.6)$ & $0.92[0.76-1.11], p=0.39$ \\
THMs written on slides, $\mathrm{n}(\%)$ & $2157(68.0)$ & $473(83.9)$ & $2.99[2.24-3.99], p<0.001$ \\
Notetaking, $\mathrm{n}(\%)$ & $1297(40.9)$ & $341(60.5)$ & $2.04[1.69-2.47], p<0.001$ \\
Slides per lecture, (number) & $57[46-60]$ & $53[44-58]$ & $0.97[0.95-0.99], p=0.008$ \\
Lecture in afternoon, $\mathrm{n}(\%)$ & $1489(46.9)$ & $242(42.9)$ & $0.92[0.52-1.65], p=0.79$ \\
Teaching experience (years) & $21.4 \pm 8.8$ & $22.6 \pm 9.3$ & $1.02[0.99-1.05], p=0.30$ \\
\hline
\end{tabular}

THM take-home message 
Table 3 Univariate analysis of residents' knowledge

\begin{tabular}{|c|c|c|c|c|c|}
\hline \multirow[b]{2}{*}{ Variable } & \multicolumn{5}{|c|}{$\begin{array}{l}\text { Performance groups (score out of } 100 \text { points) } \\
n=853\end{array}$} \\
\hline & $\begin{array}{l}\text { Mean } \pm \text { SD } \\
\text { (score/100 points) }\end{array}$ & $\begin{array}{l}\text { Low performance (<50 points) } \\
n=250(29 \%)\end{array}$ & $\begin{array}{l}\text { Medium performance } \\
(50-80 \text { points) } \\
n=359(42 \%)\end{array}$ & $\begin{array}{l}\text { High performance } \\
\text { (> } 80 \text { points) } \\
n=244 \text { (29\%) }\end{array}$ & $P$ value \\
\hline \multicolumn{6}{|l|}{ Lectures } \\
\hline Control & $63.8 \pm 26.2$ & $117(27.2)$ & $185(42.9)$ & $129(29.9)$ & \multirow[t]{2}{*}{0.75} \\
\hline Intervention & $61.1 \pm 31.4$ & $133(31.5)$ & $174(41.2)$ & $115(27.3)$ & \\
\hline \multicolumn{6}{|c|}{ Gender of resident } \\
\hline Female & $64.4 \pm 29.3$ & $75(28.1)$ & $102(38.2)$ & $90(33.7)$ & \multirow[t]{2}{*}{0.04} \\
\hline Male & $61.6 \pm 28.7$ & $175(29.9)$ & $257(43.9)$ & $154(26.3)$ & \\
\hline \multicolumn{6}{|l|}{ Notetaking } \\
\hline No & $58.5 \pm 28.9$ & $159(32.6)$ & $219(44.9)$ & $110(22.5)$ & \multirow[t]{2}{*}{$<0.001$} \\
\hline Yes & $67.9 \pm 28.0$ & $91(24.7)$ & $140(38.5)$ & $134(36.8)$ & \\
\hline \multicolumn{6}{|l|}{ THMs retention } \\
\hline$\leq 25 \%$ & $58.2 \pm 29.0$ & $217(33.9)$ & $279(43.6)$ & $144(22.5)$ & \multirow[t]{2}{*}{$<0.001$} \\
\hline$>25 \%$ & $75.2 \pm 24.7$ & $33(15.5)$ & $80(37.6)$ & $100(47.0)$ & \\
\hline
\end{tabular}

THM, take-home message

regarding the benefits thereof [18]. Implementing such changes is a long-term process that requires commitment. Targeted training for new teachers, followed by continuing education regarding new findings pertaining to the science of learning, could convince teachers to update their pedagogical approach and thus improve educational practice.

Our study had some limitations. Firstly, we did not assess the clinical impact of the knowledge acquired. However, many studies have reported a positive impact of knowledge on clinical practice [1] and none have provided any evidence to the contrary. Secondly, we did not investigate the influence of the lecture topic or the choice of lecturer on our learning outcomes. Thirdly, we did not assess the association between written THMs and residents 'knowledge because the MCQs of lecturers were not standardized according to the level of difficulty. Fourthly, we cannot rule out that the MCQs could help the residents to remember the THMs because the MCQs and THMs asked the residents were on the same form. Fifthly, the design of the study, in which the lecturer was blinded, prevented us from assessing the quality of the THMs and the intervention. Some lecturers who were randomly assigned to the control group had standard teaching practice for putting written THMs into the slide presentation when some lecturers in the intervention group unfortunately did not follow the instructions and did not put a written THM into their slide presentation. We did not want to change the real practice of some control lecturers so as not to cause a disadvantage for the control group. If the THMs in the intervention lectures have been modified before the lecture (by adding them to slide, and potentially removing them from the slide presentations delivered in the control lectures), the control lectures would have been at a disadvantage. In addition, modification of THMs by investigators who are not experts is difficult, because THMs written on slides are an integral part of a lecturer's oral presentation and cannot be standardized without introducing a high degree of artificiality. Thus, we retained real teaching conditions and sought to determine the effect of being instructed to include written THMs in presentations only on experienced teachers. In this real-life teaching situation, one third of the THMs delivered by the lecturers were not provided in written form on their slides.

\section{Conclusions}

This study showed that in lectures delivered to residents, a third of the THMs did not appear in written form on the lecturers' slides. An intervention based on an explicit instruction to lecturers to incorporate written THMs into their slide presentation did not result in increased use of written THMs into the slide presentation or improvement of the THMs retention or level of knowledge. However, the analyses performed with all THMs written on slides from the two groups of this randomized controlled study showed that there were strong positive associations between writing THMs on slides, THMs retention and knowledge of residents. Further researches are needed to assess interventions to increase written THMs in lectures by faculty. 


\section{Supplementary information}

Supplementary information accompanies this paper at https://doi.org/10. 1186/s12909-020-02092-7.

Additional file 1. List of lectures.

Additional file 2. Examples of Multiple Choice Questions.

Additional file 3. Timing of the study (Figure). Legend: THM, take-home message; MCQ: multiple choice question.

\section{Abbreviations}

aOR: adjusted Odds-Ratio; Cl: Confidence Intervals; EBM: Evidence-Based Medicine; ICU: Intensive Care Unit; MCQ: Multiple Choice Question; OR: Odds-Ratio; SD: Standard-Deviation; THM: Take-Home Message

\section{Acknowledgements}

We are indebted to Mr. Jeffrey Watts for assistance in the preparation of the manuscript.

Members of the TREX (Teaching Research) group:

Jean-François TIMSIT (Centre Hospitalier Universitaire Bichat, Médecine Intensive Réanimation, Paris); Nicolas TERZI (Centre Hospitalier Universitaire de Grenoble, Médecine Intensive Réanimation, Grenoble); Laurent PAPAZIAN (Centre Hospitalier Universitaire de Marseille, Médecine Intensive Réanimation, Marseille); Marc GAINNIER (Centre Hospitalier Universitaire de Marseille, Médecine Intensive Réanimation, Marseille); Antoine ROCH (Centre Hospitalier Universitaire de Marseille, Médecine Intensive Réanimation, Marseille); Jean-Marie FOREL (Centre Hospitalier Universitaire de Marseille, Médecine Intensive Réanimation, Marseille); Sami HRAIECH (Centre Hospitalier Universitaire de Marseille, Médecine Intensive Réanimation, Marseille); Nathanaël EISENMANN (Centre de Lutte Contre le Cancer Jean Perrin, Clermont-Ferrand); Julien BOHE (Centre Hospitalier Universitaire de Lyon, Médecine Intensive Réanimation, Lyon); Jean-Christophe RICHARD (Centre Hospitalier Universitaire de Lyon, Médecine Intensive Réanimation, Lyon); Martin COUR (Centre Hospitalier Universitaire de Lyon, Médecine Intensive Réanimation, Lyon); Fabrice ZENI (Centre Hospitalier Universitaire de SaintEtienne, Médecine Intensive Réanimation, Saint-Etienne); Guillaume THIERY (Centre Hospitalier Universitaire de Saint-Etienne, Médecine Intensive Réanimation, Saint-Etienne); Sophie PERINEL (Centre Hospitalier Universitaire de Saint-Etienne, Médecine Intensive Réanimation, Saint-Etienne); Gilles BERNARDIN (Centre Hospitalier Universitaire de Nice, Médecine Intensive Réanimation, Nice); Boris JUNG (Centre Hospitalier Universitaire de Montpellier, Médecine Intensive Réanimation, Montpellier); Olivier JONQUET (Centre Hospitalier Universitaire de Montpellier, Médecine Intensive Réanimation, Montpellier); Stein SILVA (Centre Hospitalier Universitaire de Toulouse, Médecine Intensive Réanimation, Toulouse)

\section{Authors' contributions}

$A L, B S$ and $B P$ conceived and designed the study; $A L$ recruited the participants and collected the data; $A B, D G$ and JD established the takehome messages accordances; LA, CS, BT, PV, BM, PS, PC, JS, YB, CG; MD; KK delivered lectures and gave take-home messages and multiple choice questions. $\mathrm{AL}, \mathrm{BP}$ analysed and interpreted data; $\mathrm{AL}, \mathrm{AB}, \mathrm{MD}, \mathrm{CG}, \mathrm{BS}, \mathrm{JD}$ and $\mathrm{BP}$ drafted the report and all authors contributed to review it. All authors approved the final version.

\section{Funding}

No Grant

\section{Availability of data and materials}

The data that support the findings of this study are available from the corresponding author upon reasonable request.

\section{Ethics approval and consent to participate}

Approved by the ethics committee of the French Intensive Care Society (CE SRLF, No.12-394) and the Institutional Review Board of Comité Pour la Protection des Personnes Sud-Est 6 (IRB00008526, No.201837).

\section{Consent for publication}

Not applicable.

\section{Competing interests}

Dr. Darmon report having received consulting fees from Sanofi and GileadKite, research support from Astute Medical and MSD, and speaker fees from MSD, Gilead-Kite and Astellas. The others authors have no financial conflicts of interest related to this study.

\section{Author details}

${ }^{1}$ Intensive Care Medicine, Gabriel Montpied Hospital, University Hospital of Clermont-Ferrand, Clermont-Ferrand, France. ${ }^{2}$ Intensive Care Unit, Centre Jean Perrin, Clermont-Ferrand, France. ${ }^{3}$ LMGE «Laboratoire Micro-organismes: Génome et Environnement», UMR CNRS 6023, Clermont-Auvergne University, Clermont-Ferrand, France. ${ }^{4}$ Intensive Care Unit, Pellegrin-Tripode Hospital, University Hospital of Bordeaux, Bordeaux, France. ${ }^{5}$ Intensive Care Unit, Edouard Herriot Hospital, University Hospital of Lyon, Lyon, France. Intensive Care Unit, Albert Michallon Hospital, University Hospital of Grenoble, Grenoble, France. ${ }^{7}$ Clinical Investigation Center-CIC 1408, Nord Teaching Hospital, University Hospital of Saint-Etienne, Saint-Etienne, France. ${ }^{8}$ Medical-Surgical Intensive Care Unit, Dupuytren Hospital, University Hospital of Limoges, Limoges, France. ${ }^{9}$ Department of Medical and Toxicological Critical Care, Lariboisière Hospital, Assistance Publique - Hopitaux de Paris, INSERM UMRS-1144, Paris-Diderot University, Paris, France. ${ }^{10}$ Intensive Care Unit, Department of Anaesthesiology, Gabriel Montpied Hospital, University Hospital of Clermont-Ferrand, Clermont-Ferrand, France. ${ }^{11}$ Department of Radiology, Gabriel Montpied Hospital, University Hospital of

Clermont-Ferrand, Clermont-Ferrand, France. ${ }^{12}$ Adult Emergency Department, Gabriel Montpied Hospital, University Hospital of Clermont-Ferrand, Clermont-Ferrand, France. ${ }^{13}$ Nutrition Unit, Gabriel Montpied Hospital, University Hospital of Clermont-Ferrand, Clermont-Ferrand, France. ${ }^{14}$ Intensive Care Unit, Croix Rousse Hospital, University Hospital of Lyon, Lyon, France. ${ }^{15}$ Intensive Care Unit, Nord Teaching Hospital, University Hospital of Saint-Etienne, Saint-Etienne, France. ${ }^{16}$ Intensive Care Unit, Lapeyronie Hospital, University Hospital of Montpellier, Montpellier, France.

${ }^{17}$ Medical Intensive Care Unit, Gabriel Montpied Hospital, University Hospital of Clermont-Ferrand, Clermont-Ferrand, France. ${ }^{18}$ Intensive Care Unit, I'Archet Hospital, Cote d'Azur University, Nice, France. ${ }^{19}$ Biostatistics unit, Delegation à la Recherche Clinique (DRCl), University Hospital of Clermont-Ferrand, Clermont-Ferrand, France.

Received: 5 March 2020 Accepted: 28 May 2020

Published online: 03 June 2020

\section{References}

1. Boonyasai RT, Windish DM, Chakraborti C, Feldman LS, Rubin HR, Bass EB. Effectiveness of teaching quality improvement to clinicians: a systematic review. JAMA. 2007;298:1023-37.

2. Chatterjee S, Desai S, Manesh R, Sun J, Nundy S, Wright SM. Assessment of a simulated case-based measurement of physician diagnostic performance. JAMA Netw Open. 2019:2:e187006.

3. Vignon P, Pegot B, Dalmay F, Jean-Michel V, Bocher S, L'her E, et al. Acceleration of the learning curve for mastering basic critical care echocardiography using computerized simulation. Intensive Care Med. 2018; 44:1097-105.

4. Crabtree EA, Brennan E, Davis A, Squires JE. Connecting education to quality: engaging medical students in the development of evidence-based clinical decision support tools. Acad Med J Assoc Am Med Coll. 2017:92:83-6.

5. $\quad$ Singer SR, Bonvillian WB. Two revolutions in learning. Science. 2013;339: 1359

6. Kulier R, Gülmezoglu AM, Zamora J, Plana MN, Carroli G, Cecatti JG, et al. Effectiveness of a clinically integrated e-learning course in evidence-based medicine for reproductive health training: a randomized trial. JAMA. 2012; 308:2218-25.

7. Dolbow J. A modern twist on the traditional neurology textbook. Lancet Neurol. 2018:09.

8. Schwartz A, Weiner SJ, Harris IB, Binns-Calvey A. An educational intervention for contextualizing patient care and medical students' abilities to probe for contextual issues in simulated patients. JAMA. 2010:304:1191-7.

9. Prasad V. Perspective: beyond storytelling in medicine: an encounter-based curriculum. Acad Med J Assoc Am Med Coll. 2010;85:794-8.

10. Ahmadi S-F, Baradaran HR, Ahmadi E. Effectiveness of teaching evidencebased medicine to undergraduate medical students: a BEME systematic review. Med Teach. 2015;37:21-30. 
11. Davis J, Crabb S, Rogers E, Zamora J, Khan K. Computer-based teaching is as good as face to face lecture-based teaching of evidence based medicine: a randomized controlled trial. Med Teach. 2008;30:302-7.

12. Pelloux S, Grégoire A, Kirmizigul P, Maillot S, Bui-Xuan B, Llorca G, et al. Peripheral venous catheter insertion simulation training: a randomized controlled trial comparing performance after instructor-led teaching versus peer-assisted learning. Anaesth Crit Care Pain Med. 2017;36:397-402

13. Archambault PM, Thanh J, Blouin D, Gagnon S, Poitras J, Fountain R-M, et al. Emergency medicine residents' beliefs about contributing to an online collaborative slideshow. CJEM. 2015;17:374-86.

14. Lautrette A, Schwebel C, Gruson D, Talbot RW, Timsit J-F, Souweine B. Transfer of take-home messages in graduate ICU education. Intensive Care Med. 2011;37:1323-30.

15. Mayer RE. Applying the science of learning to medical education. Med Educ. 2010:44:543-9.

16. Larocque N, Kenny S, Mclnnes MDF. Medical school radiology lectures: what are determinants of lecture satisfaction? AJR Am J Roentgenol. 2015;204: 913-8.

17. Mayer RE, Mathias A, Wetzell K. Fostering understanding of multimedia messages through pre-training: evidence for a two-stage theory of mental model construction. J Exp Psychol Appl. 2002;8:147-54.

18. Guérin C, Beuret P, Constantin JM, Bellani G, Garcia-Olivares P, Roca O, et al. A prospective international observational prevalence study on prone positioning of ARDS patients: the APRONET (ARDS prone position network) study. Intensive Care Med. 2018;44:22-37.

\section{Publisher's Note}

Springer Nature remains neutral with regard to jurisdictional claims in published maps and institutional affiliations.

Ready to submit your research? Choose BMC and benefit from:

- fast, convenient online submission

- thorough peer review by experienced researchers in your field

- rapid publication on acceptance

- support for research data, including large and complex data types

- gold Open Access which fosters wider collaboration and increased citations

- maximum visibility for your research: over $100 \mathrm{M}$ website views per year

At $\mathrm{BMC}$, research is always in progress.

Learn more biomedcentral.com/submissions 